\title{
Faktor-faktor yang Mempengaruhi Tingginya Angka Kematian di IGD Rumah Sakit
}

\section{Factors Affecting High Mortality at Hospital's Emergency Room}

\author{
Rudy Limantara ${ }^{1}$, Herjunianto ${ }^{2}$, Arma Roosalina $^{1}$ \\ ${ }^{1}$ Program Studi Magister Manajemen Rumah Sakit Fakultas Kedokteran Universitas Brawijaya Malang \\ ${ }^{2}$ Rumah Sakit Angkatan Laut Dr. Ramelan Surabaya
}

\begin{abstract}
ABSTRAK
Angka kematian pada Instalasi Gawat Darurat merupakan indikator penting kinerja rumah sakit. Data angka kematian pada tahun 2013 sangat tinggi, baik GDR, NDR maupun kematian di IGD $\leq 24$ jam. Kajian dilakukan untuk mengevaluasi penyebab masalah tingginya angka kematian $\leq 24$ jam di IGD. Untuk mencari akar penyebab masalah digunakan analisis tulang ikan (fishbone) dengan data dari observasi, wawancara yang dibahas melalui FGD. Dalam memilih alternatif solusi digunakan teori tapisan Mc Namara. Gambaran pola kematian menunjukkan kematian terbesar pada 6-12 jam pertama yang juga dipengaruhi jenis morbiditas dan usia pasien. Analisis akar masalah mengidentifikasi faktor pre-hospital, sumberdaya manusia, dan kinerja monitoring komite mutu sebagai determinan keterlambatan penanganan yang dapat meningkatkan risiko kematian. Faktor kontributor utama adalah belum optimalnya standar prosedur operasional pengelolaan emergency meskipun response time sudah cukup optimal sehingga perlu dilakukan emergency drill secara berkala.
\end{abstract}

Kata Kunci: Angka kematian, emergency drill, Instansi Gawat Darurat (IGD), Standar Prosedur Operasional (SPO)

\begin{abstract}
Mortality in the Emergency Room is an important indicator of the hospital performance. Mortality number in 2013 was very high, both Gross Death Rate and Net Death Rate, and also mortality in ER within the first 24 hours. The research was conducted to evaluate the cause of high mortality problem in ER within the first 24 hours. To find the cause of the problem, fishbone analysis was used from observation and interviews discussed through the FGD. In choosing alternative solution, Mc Namara theory was used. Illustration of mortality patterns shows the highest death in the first 6-12 hours which is also affected by the morbidity type and age of the patient. Cause analysis identifies pre-hospital factors, human resources, and quality monitoring committee performance as a determinant of the delays in treatment that can increase the risk of death. The main contributing factor is the non-optimal management of standard operating procedures of emergency although response time was optimal enough, so emergency drills should be conducted regularly.
\end{abstract}

Keywords: Emergency drill, Emergency Room (ER), mortality rates, Standard Operating Procedure (SOP)

Jurnal Kedokteran Brawijaya, Vol. 28, Suplemen No. 2, 2015; Korespondensi: Rudy Limantara. Program Studi Magister Manajemen Rumah Sakit Fakultas Kedokteran Universitas Brawijaya Malang, Jl. Veteran Malang 65145 Tel. (0341) 569117 Email: rudy.limantara@yahoo.com 


\section{PENDAHULUAN}

Instalasi gawat darurat merupakan ujung tombak pelayanan rumah sakit yang terus meningkat jumlah pasiennya, baik karena kurangnya staf, kurangnya tempat tidur, proses operasional yang buruk, kurangnya akses universal terhadap pencegahan dan perawatan primer, penutupan dan konsolidasi rumah sakit dan trauma centre. Persoalan yang kompleks dan fenomena multi disiplin ini mengakibatkan lambatnya penanganan pasien, peningkatan waktu tunggu, ketidakpuasan pasien, rasa sakit dan penderitaan berkepanjangan, tertundanya pengobatan dan perawatan pasien, peningkatan jumlah pasien yang pulang tanpa pelayanan, kelelahan dokter dan staf, serta bisa menimbulkan kekerasan dan frustasi (1-9).

Kematian adalah salah satu indikator mutu pelayanan kesehatan yang penting. World Health Organization (WHO) menyatakan bahwa dari tahun 2005-2010 diperkirakan terdapat 850 kematian per 100.000 penduduk yang terjadi setiap tahunnya (10). Di Inggris dan Wales pada tahun 2005 lebih kurang 73\% dari total kematian terjadi di fasilitas pelayanan kesehatan rumah sakit. Tingginya angka kematian di rumah sakit merupakan pertanda kemungkinan adanya masalah mutu pelayanan yang memerlukan tindakan perbaikan, dan kurang lebih $22,7 \%$ kematian yang terjadi di rumah sakit sebenarnya dapat dihindarkan dengan perawatan yang optimal (1113).

Menteri Kesehatan sudah menetapkan standar pelayanan minimal rumah sakit tahun 2008. Salah satu pelayanan yang dinilai adalah angka kematian pada rumah sakit, yaitu kematian kurang dari 48 jam, lebih dari 48 jam dan kurang dari 24 jam $(14,15)$. Net Death Rate (NDR) adalah kematian yang lebih dari 48 jam setelah pasien dirawat di rumah sakit (16). NDR yang tinggi menggambarkan mutu yang kurang di suatu rumah sakit. Mutu yang kurang ini, dapat disebabkan oleh faktor input rumah sakit, pasien serta lingkungan. Mutu pelayanan kesehatan umumnya dikaitkan dengan pelayanan kesehatan kepada perorangan yang diberikan oleh suatu institusi atau fasilitas kesehatan seperti rumah sakit (17).

Rumah Sakit (RS) X merupakan rumah sakit milik Pemerintah Kabupaten tipe $C$ dan telah ditetapkan sebagai Badan Layanan Umum Daerah (BLUD) dengan 266 buah tempat tidur. Gambaran tingkat pemanfaatan dan efisiensi sarana pelayanan serta mutu pelayanan pada tahun 2013 menunjukkan gambaran sebagai berikut: BOR (Bed Occupancy Rate) 69,82\%, TOI (Turn Over Interval) 1,55 hari, BTO (Bed Turn Over) 71,09 kali, Average Long of Stay (ALOS) 3,49 hari, NDR (Net Death Ratio) $61,40 \%$ dan GDR (Gross Death Rate) $127,48 \%$. Pada tahun 2013, jumlah kunjungan rawat jalan adalah 109.549 pasien, Instalasi Gawat Darurat (IGD) sejumah 15.512 pasien dan rawat inap sejumlah 19.061 pasien dengan tren yang semakin meningkat dari tahun-tahun sebelumnya (1). Bila dibandingkan dengan standar menunjukkan tingkat efisiensi yang cukup namun masih menunjukkan angka kematian yang tinggi.

IGD merupakan instalasi yang memberikan pelayanan pertama yang bersifat emergency pada pasien dengan ancaman kematian dan kecacatan secara terpadu dengan melibatkan multi disiplin ilmu. Pelayanan di IGD merupakan layanan yang bersifat integratif dengan melibatkan sejumlah tenaga kesehatan secara bersama- sama untuk memberikan pelayanan kepada pasien. Apabila kematian di IGD tinggi, hal ini berarti mutu rumah sakit tersebut kurang baik, kepercayaan masyarakat menurun, pencitraan rumah sakit menurun, sehingga bisa menurunkan kunjungan ulang pasien dan turunnya pendapatan rumah sakit.

Angka kematian di IGD yang tinggi dapat menimbulkan aspek hukum bagi rumah sakit, baik direktur, tenaga medis, paramedis dan tenaga lainnya yang terlibat. Kematian pasien ini sebagian dapat dicegah dan sebagian lagi tidak dapat dicegah. Bila terjadi kematian yang seharusnya bisa dicegah, berarti terdapat kesalahan di rumah sakit. Kesalahan ini bisa karena faktor rumah sakit atau sumber daya manusia (SDM) yang bekerja di rumah sakit tersebut.Kesalahan yang dilakukan oleh SDM secara umum ada 3 macam, yaitu: pertama adalah intentional professional misconduct, yaitu apabila yang bersangkutan dengan sengaja tidak melakukan tindakan sesuai standar yang ada tanpa unsur kealpaan; kedua adalah negligence, yaitu ketidak sengajaan/kelalaian, dimana seseorang lalai melakukan sesuatu padahal itu seharusnya dilakukan sehingga menimbulkan masalah kesehatan bagi pasien; ketiga adalah lack of skill, yaitu orang tersebut melakukan sesuatu diluar kompetensinya. Ketiga macam kelalaian tersebut bisa berakibat hukum pada $\mathrm{sdm}$ yang bersangkutan (18).

Studi pendahuluan di rumah sakit magang ini mendapatkan bahwa angka kematian kurang dari 24 jam pada IGD masih tinggi, yaitu sebesar $7 \%$ (standar kurang dari $2 \%$ ) pada tahun 2013 dengan lima penyebab kematian yang terbanyak adalah Cerebro Vascular Accident (CVA), Cedera Otak Berat (COB), Infark Miokard Akut (IMA), Meningitis dan Sepsis. Banyaknya pasien IGD yang meninggal ini bisa menyebabkan penurunan kualitas layanan, penurunan kepuasan pasien, patient safety terancam dan resiko tuntutan hukum. Penelitian dilakukan untuk mengeksplorasi penyebab tingginya angka kematian di IGD ini sebagai dasar dalam mengembangkan alternatif solusi serta strategi implementasi.

\section{METODE}

Studi dilakukan pada kurun waktu bulan Agustus-Oktober 2014 dengan pendekatan participatory action research yang dilakukan dalam dua tahapan. Tahapan pertama dilakukan untuk mengidentifikasi alur pelayanan IGD serta potensi permasalahan sebagai dasar dalam mengidentifikasi akar masalah. Metode yang digunakan pada tahap pertama adalah observasi,wawancara dan studi dokumen.

Observasi dilakukan pada proses layanan di IGD dengan mengikuti alur pasien dan mengamati kendala yang mungkin terjadi. Wawancara dilakukan pada dokter penanggung jawab IGD, para dokter jaga IGD, perawat koordinator IGD, para perawat IGD, pasien dan keluarganya. Dalam wawancara tersebut ditanyakan tentang tahapan berobat di IGD dari pendaftaran sampai penanganan, kendala serta keluhan dari pasien yang mungkin timbul. Dokumen yang diamati adalah dokumen SPO IGD, dokumen akreditasi IGD, dokumen laporan tahunan RS $X$ dan laporan rekam medik. Penentuan akar masalah menggunakan metode "fishbone analysis" berdasarkan data temuan yang didapatkan. Dengan metode ini dapat menunjukkan rangkaian penyebab masalah sampai akar dari suatu masalah. Tahap kedua adalah identifikasi alternatif solusi permasalahan dan 
pemilihan solusi, dilakukan melalui diskusi dengan pembimbing lapangan dan staf terkait. Selanjutnya dilakukan pemilihan solusi utama dengan mempertimbangkan efektifitas, sfisiensi biaya dan kemudahan pelaksanaannya. Solusi yang terpilih kemudian dilakukan uji coba melalui sosialisasi dan pelatihan. Solusi yang telah diujikan diajukan sebagai rekomendasi untuk implementasi dilengkapi dengan pedoman teknis.

\section{HASIL}

\section{Deskripsi Mortalitas pada Instalasi Gawat Darurat}

Dari data sekunder yang diperoleh, diketahui bahwa angka mortalitas terbesar adalah pada kasus Sepsis, diikuti kasus CVA, COB, Meningitis dan IMA (Tabel 1). Setelah mempelajari data rekam medik dari 37 kasus tersebut, ada beberapa yang dikeluarkan dari sampel baik karena ketiadaan rekam medik, diluar diagnosis kasus yang diteliti, dan keluar dari batas waktu meninggalnya pasien, sehingga hanya didapatkan 27 sampel. Dari 27 sampel tersebut, kasus CVA terdapat 14 pasien $(51,9 \%)$, kasus COB terdapat 7 pasien $(25,9 \%)$, kasus Sepsis terdapat 4 pasien $(14,8 \%)$, kasus IMA terdapat 1 pasien $(3,7 \%)$ dan kasus Meningitis terdapat 1 pasien $(3,7 \%)$.

Dari 27 kasus tersebut, terdapat 4 kasus $(14,9 \%)$ yang tidak dilakukan triase, terdapat $24(88,9 \%)$ kasus yang tidak mencantumkan response time pelayanan. Dari asal pasien, terdapat 15 kasus $(55,6 \%)$ yang dirujuk, terdiri dari $26,7 \%$ dirujuk dari rumah sakit, 66,7\% dirujuk dari puskesmas, dan $6,7 \%$ dirujuk dari klinik swasta.

Tabel 1. Data jumlah kasus kematian dan mortalitasnya periode Januari-Nopember 2014

\begin{tabular}{clccc}
\hline No. & Diagnosis & Jumlah Kematian & Jumlah Kasus & Mortalitas \\
\hline 1 & CVA & 18 & 500 & 0,036 \\
2 & COB & 11 & 488 & 0,029 \\
3 & IMA & 2 & 381 & 0,004 \\
4 & Meningitis & 1 & 34 & 0,029 \\
5 & Sepsis & 5 & 23 & 0,217 \\
\hline
\end{tabular}

Sumber: Rekam Medik RSX

Tabel 2 menunjukkan waktu terjadinya kematian pada 5 diagnosis tersebut, dimana dibagi tiap 6 jam. Pembagian menjadi 6 jam ini merupakan masa penting karena proses kerusakan jaringan otak dan iskemik dapat terjadi dan kematian paling banyak terjadi.Data menunjukkan kematian pasien terbanyak terjadi pada 6 jam pertama untuk kasus CVA, COB, dan sepsis. Untuk kasus IMA dan meningitis, kematian terjadi pada 6 jam kedua.

Tabel 2. Lama terjadinya kematian sejak pasien masuk per kasus

\begin{tabular}{lllllll}
\hline No. & $\begin{array}{l}\text { Waktu Terjadinya } \\
\text { Kematian }\end{array}$ & CVA & COB & IMA & Meningitis & Sepsis \\
\hline 1 & Kurang dari 6 jam & $64,3 \%$ & $71,4 \%$ & & & $100 \%$ \\
2 & 6 - kurang dari12 jam & $14,3 \%$ & & $100 \%$ & $100 \%$ & \\
3 & 12 - kurang dari18 jam & $7,1 \%$ & $14,3 \%$ & & & \\
4 & 18 - kurang dari 24 jam & $7,1 \%$ & & & & \\
5 & Tidak Tercatat & $7,1 \%$ & $14,3 \%$ & & & \\
\hline
\end{tabular}

Sumber: Rekam Medik RSX
Tabel 3 menunjukkan usia pasien saat meninggal perkasus. Pada kasus CVA usia pasien terbanyak adalah pada rentang usia lebih dari 50 tahun yaitu sebanyak $64,3 \%$. Hal ini sesuai dengan faktor predisposisi terjadinya kasus CVA yaitu pada usia lebih dari 50 tahun. Pada kasus COB usia pasien terbanyak adalah pada rentang usia diatas 40 tahun. Pada kasus sepsis, usia pasien terbagi sama besar antara kurang dari 10 tahun dan lebih dari 50 tahun. Secara keseluruhan data pola kematian menunjukkan adanya pengaruh faktor usia, kegawatan, kecepatan penanganan yang juga dipengaruhi faktor pre-hospital.

Tabel 3. Usia pasien pada saat meninggal

\begin{tabular}{|c|c|c|c|c|c|c|}
\hline No & $\begin{array}{c}\text { Usia Pada Waktu } \\
\text { Terjadinya Kematian }\end{array}$ & CVA & COB & IMA & Meningitis & Sepsis \\
\hline 1 & 0 - kurang dari 10 tahun & & & & & $50 \%$ \\
\hline 2 & 10 - kurang dari 20 tahun & & $14,3 \%$ & & & \\
\hline 3 & 20 - kurang dari 30 tahun & & $14,3 \%$ & $100 \%$ & & \\
\hline 4 & 30 - kurang dari 40 tahun & $21,4 \%$ & $14,3 \%$ & & & \\
\hline 5 & 40 - kurang dari 50tahun & $14,3 \%$ & $28,6 \%$ & & & \\
\hline 6 & Lebih dari 50 tahun & $64,3 \%$ & $28,6 \%$ & & $100 \%$ & $50 \%$ \\
\hline
\end{tabular}

\section{Identifikasi Akar Masalah}

Dari hasil pengamatan langsung, wawancara dengan petugas rumah sakit dan telusur data sekunder, ditemukan beberapa penyebab tingginya angka kematian di IGD. Dengan metode "analisis fishbone" dapat ditelusuri beberapa akar masalah (Gambar 1).

Pada Gambar 1, fishbone diagram, terdapat beberapa akar masalah yang bisa mengakibatkan tingginya angka kematian kurang dari 24 jam di IGD. Penyebab pertama adalah keluarga pasien tidak mengetahui kondisi kesehatan pasien yang sudah parahsehingga mereka lambat merujuk ke rumah sakit. Selain ketidak tahuan tersebut, adanya kekhawatiran terhadap besarnya biaya yang harus ditanggung dan sulitnya transportasi umum terutama pada malam hari merupakan salah satu akar permasalahan. Kendaraan umum tersebut takut mendapatkan bala/kesialan kalau pasien meninggal di kendaraan mereka, juga takut dianggap sebagai pihak yang menabrak.

Penanda yang menunjukkan lokasi rumah sakit ditemukan sangat sedikit menjadi penyebab kedua.Bangunan IGD terletak di tengah-tengah lokasi RS X, menimbulkan kesan agak tersembunyi, meskipun tata ruangnya sudah sesuai dengan Pedoman Teknis Bangunan RS Ruang Gawat Darurat Kementerian Kesehatan Tahun 2012. Pasien atau keluarganya yang dalam kondisi terburu-buru, bisa terlewatkan jalan menuju IGD meskipun sudah memiliki jalan akses masuk dan keluar tersendiri.

Penyebab selanjutnya adalah kondisi kesehatan pasien yang sudah buruk bisa bertambah buruk bilamana fasilitas kesehatan tingkat pertama yang memberikan pertolongan pertama, tidak memiliki sarana prasarana yang memadai. Wawancara dari koordinator perawat IGD, seringkali pasien datang dengan kondisi dikirim tanpa mendapatkan pertolongan yang baik karena keterbatasan obat-obatan di fasilitas kesehatan tingkat pertama. Selain itu hasil observasi di lapangan menemukan triase dilakukan oleh satu orang perawat senior dan beberapa mahasiswa 


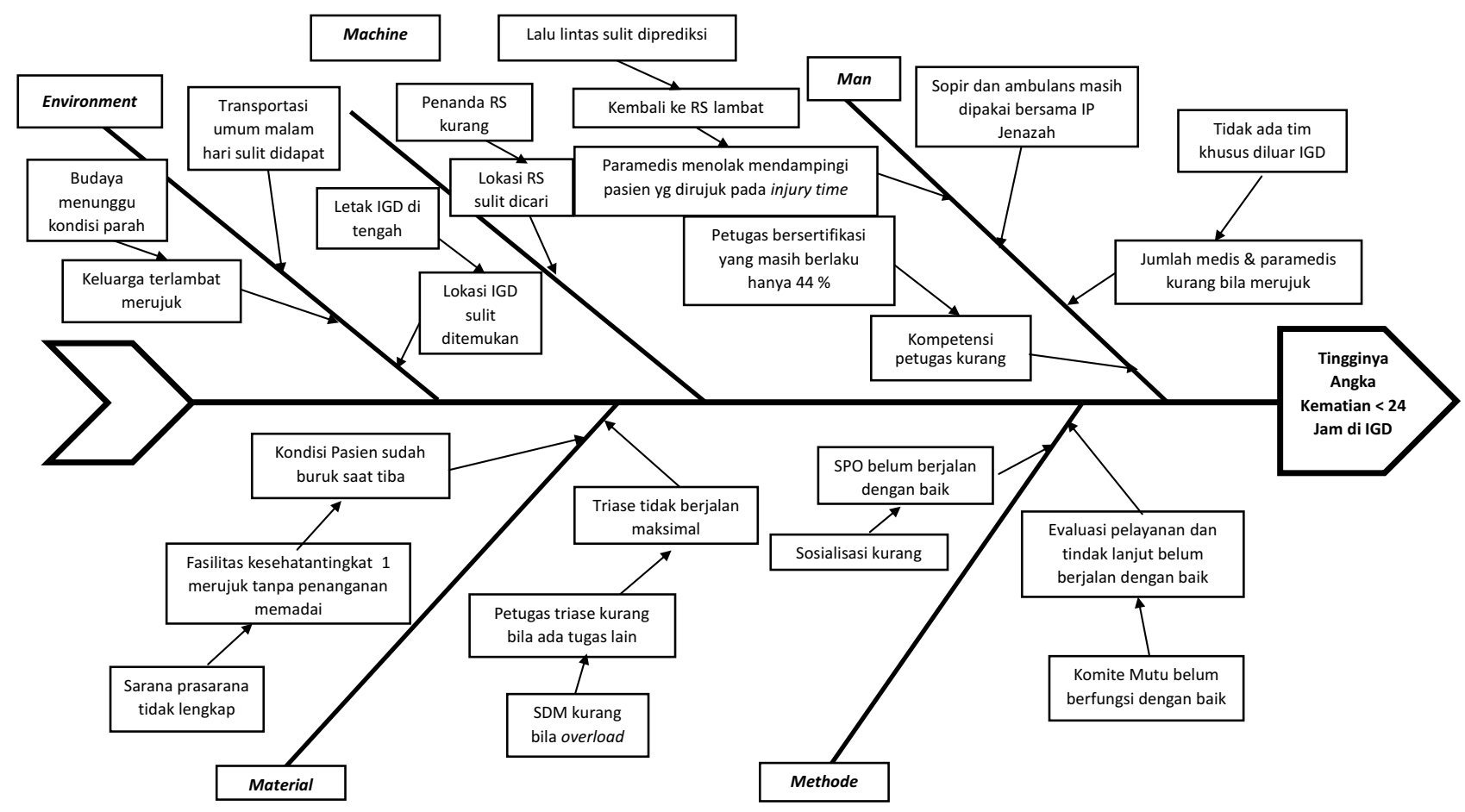

Gambar 1. Fishbone diagram

perawat. Bilamana perawat senior tersebut mendapatkan tugas lainnya seperti mengantarkan pasien ke penunjang medik, maka yang bertugas triase adalah mahasiswa perawat saja. Hal ini bisa terjadi bila kondisi IGD overload dengan pasien.

Faktor ketepatan respon menjadi pertimbangan penting disamping kecepatan. Meskipun response time pelayanan di IGD tidak melebihi dari lima menit, tetapi tidak sesuai dengan Standar Prosedur Operasional (SPO) Triase yang mengarahkan pasien dengan gangguan $A B C$ berat dan kesadaran menurun langsung ke bilik P1 dengan keterangan yang jelas. Penanganan pasien P1 juga kadang-kadang melupakan tindakan resiko pasien jatuh dengan membiarkan rel tempat tidur tidak terpasang. Penanganan ABC pasien P1 tidak ditangani dengan benar sejak dari ambulans pengirim yang tidak memberikan oksigen, brankar IGD tidak terdapat tabung oksigen dan selama di triase juga tidak diberikan dan hal ini disaksikan oleh dokter IGD yang memeriksa dan para dokter muda serta paramedis senior yang melakukan tugasnya. Brankar juga tidak mempunyai tiang penyangga cairan infus, sehingga sejak turun dari ambulans, pemberian cairan tidak dilakukan dengan baik. Pada aspek metode ditemukan bahwa evaluasi kinerja IGD sudah dilakukan setiap 3 bulan dan dilaporkan ke atasannya, namun, penelusuran data sekunder di IGD, tidak ditemukan adanya umpan balik dari manajemen. Hal ini mengindikasikan belum optimalnya kinerja komite mutu.

Jumlah ketenagaan di IGD sudah sesuai dengan persyaratan depkes, dimana dokter spesialis sudah lebih dari 4 orang, dokter umum 13 orang, perawat 26 orang. Berdasarkan hasil wawancara dengan Koordinator Perawat IGD dan dokter jaga IGD, pola ketenagaan ini sudah mencukupi pada kondisi tidak ada pasien yang perlu dirujuk keluar RS X karena tidak terdapat tim khusus yang mendampingi sehingga memakai tenaga dari IGD. Kegiatan pelayanan merujuk pasien ini juga berhubungan dengan unit kerja lain yaitu ambulans dan sopirnya. Karena sopir ambulans masih menjadi satu dengan Instalasi Pemulasaraan Jenazah, pelayanan IGD harus menyesuaikan dengan jadwal sopir ambulans jenazah dengan memprioritaskan IGD. Dari sisi kualitas, kompetensi petugas IGD masih kurang, karena petugas yang bersertifikat yang masih berlaku hanya sebanyak $44 \%$ dan terdapat 1 orang perawat yang belum memiliki pelatihan sama sekali. Meskipun pelayanan di IGD sudah berlangsung dengan baik, tetapi dengan melakukan update keilmuan, diharapkan bisa menurunkan angka kematian di IGD. Hasil wawancara juga menjelaskan bahwa pelayanan merujuk pasien ini bilamana mendekati waktu pergantian dinas, maka sering terjadi penundaan keberangkatan sampai petugas dinas berikutnya datang. Hal ini berdasarkan pertimbangan lokasi rumah sakit tujuan yang lalu lintasnya seringkali macet sehingga petugas baru bisa kembali ke RS $X$ beberapa jam setelah masa dinasnya selesai. Kondisi pasien yang gawat yang memerlukan penanganan segera di rumah sakit rujukan bisa meninggal karena penundaan ini.

\section{Identifikasi Alternatif dan Penetapan Solusi Masalah}

Identifikasi alternatif solusi permasalahan dan pemilihan solusi dilakukan melalui diskusi dengan perwakilan manajer rumah sakit, Koordinator Perawat serta dokter IGD. Terdapat beberapa alternatif solusi masalah yang diidentifikasi. Alternatif pertama adalah membentuk tim khusus untuk pelayanan merujuk pasien yang terdiri dari, dokter umum, perawat, pekarya dilengkapi dengankendaraan ambulans dan sopir ambulans dengan sifat tersedia dalam 24 jam operasional, sehingga tidak mengganggu pelayanan di IGD yang sudah ada. Selain itu, tim ini juga bisa melayani panggilan kegawat daruratan dari masyarakat sekitar yang kesulitan transportasi bilamana malam hari, sehingga pasien bisa dilayani dengan lebih baik. Untuk meningkatkan akses dan kecepatan perlu dilakukan penambahan penanda- 
penanda yang mudah terlihat pada lokasi-lokasi strategis sekitar RS X serta di dalam lokasi rumah sakit untuk membantu identifikasi lokasi IGD dengan mudah.

Disamping faktor di rumah sakit, faktor prehospital juga sangat penting. Oleh karena itu perlu rekomendasi kepada Dinas Kesehatan Kabupaten X untuk melakukan pelatihan sumber daya manusia tentang kegawat daruratan dan melengkapi semua sarana prasarana kegawat daruratan pada fasilitas kesehatan tingkat pertama. Disamping itu tetap perlu dilakukan pelatihan semua sumber daya manusia IGD RS X dibidang kegawat daruratan agar target petugas yang bersertifikasi yang masih berlaku mencapai $100 \%$. Upaya penguatan sumberdaya manusia perlu ditunjangan dengan pengaturan formasi ketenagaan pada petugas triase agar petugas yang kompeten bisa selalu tersedia pada saat ada pasien datang sertasosialisasi SPO dan emergency drill agar semua pasien dapat penanganan yang maksimal sesuai dengan kebutuhannya. Semua upaya tersebut harus didukung dengan monitoring dan evaluasi berkelanjutan melalui penguatan fungsi komite mutu.

\section{DISKUSI}

Hasil penelitian menunjukkan bahwa kasus kematian terbanyak adalah CVA kemudian diikuti COB dan pada Tabel 2 terlihat bahwa kematian kebanyakan terjadi pada kurang dari 6 jam pertama. Hal ini sesuai dengan penelitian Ratnaningsih dalam Susilawati yang menyatakan bahwa waktu 6 jam setelah serangan merupakan masa penting karena proses kerusakan jaringan otak dan iskemik dapat terjadi dan kematian paling banyak terjadi pada masa ini. Penelitian oleh Boto dan Singh dalam Susilawati tersebut juga mengungkapkan $20 \%$ kasus COB meninggal dunia pada 6 jam pertama (19). Hasil juga menunjukkan bahwa usia pasien pada kasus CVA, kebanyakan lebih dari 50 tahun, hal ini sesuai dengan faktor predisposisi pada beberapa penelitian (20-27). Pada kasus COB, usia pasien terbanyak diatas 40 tahun.

Profil kematian pada IGD menunjukkan pentingnya kecepatan penanganan tidak hanya saat di IGD tetapi juga faktor pre-hospital diantaranya kecepatan pengenalan kegawatan dan rujukan. Salah satu faktor yang menyebabkan keterlambatan pencarian pertolongan kesehatan ke IGD yang ditemukan dalam penelitian ini adalah budaya masyarakat yang menunggu hingga kondisi kesehatan pasien menjadi parah. Hal ini memang sesuai dengan penelitian yang dilakukan oleh Sunanti dan Soejoeti yang menyatakan bahwa istilah sehat mengandung banyak muatan kultural, sosial dan pengertian profesional yang beragam. Persepsi mengenai

\section{DAFTAR PUSTAKA}

1. Rumah Sakit X. Laporan Tahunan RS X Tahun 2013. Bangil: RSX; 2014.

2. Flabouris A, Jeyadoss J, Field J, and Soulsby T. Direct and Delayed Admission to an Intensive Care or High Dependency Unit Following Discharge from the Emergency Department: Associated Patient Characteristics and Hospital Outcomes. Critical Care and Resuscitation. 2012; 14(3): 191-197.

3. Molyneux E, Shafique A, and Robertson A. Improved Triage and Emergency Care for Children Reduces Inpatient Mortality in a Resource-Constrained Setting. terjadinya penyakit berbeda antar daerah karena berbeda kebudayaan yang ada dan berkembang dalam masyarakat tersebut (28). Pasien yang sedang sakit berat bisa saja dianggap sakit ringan karena budaya masyarakatnya mengganggap seperti itu.

Kemudahan akses juga menjadi faktor keterlambatan yang diantara dipengaruhi oleh faktor bangunan. Dari sisi arsitektur bangunan IGD menurut Kementerian Kesehatan tahun 2012, disebutkan bahwa lokasi bangunan ruang gawat darurat harus dapat mudah dikenal dari jalan raya baik dengan penggunaan pencahayaan lampu atau tanda arah lainnya (29). Pada IGD RS X, lokasinya terletak ditengah area rumah sakit, sehingga dari jalan raya agak sulit terlihat keberadaannya. Lokasi penanda keberadaan rumah sakit juga dirasakan kurang.

Dari hasil pengamatan, petugas triase kadang-kadang tidak berada di tempat dan tugasnya digantikan oleh mahasiswa perawat. Pelaksanaan triase sebaiknya dilakukan oleh petugas yang terlatih agar bisa melakukan analisa keadaan pasien sesegera mungkin sehingga dapat memberikan pertolongan yang tepat dan bisa menekan angka mortalitas (3-5,11,30-32). Petugas triase yang kompeten ini, bilamana disertai dengan penanganan sesuai SPO, maka diharapkan bisa menekan angka mortalitas di IGD.

Hasil wawancara mengungkapkan IGD sering menerima pasien rujukan tanpa diberikan sarana prasarana memadai sesuai kasusnya. Hal ini terjadi karena keterbatasan dari fasilitas kesehatan asal pasien. Karena kematian di IGD juga sangat dipengaruhi akan kondisi pasien sejak dirujuk, maka untuk menekan angka kematian di IGD, diharapkan fasilitas kesehatan tingkat pertama juga bisa dilengkapi dengan sarana prasarana memadai.

Proses untuk menurunkan tingginya angka kematian di IGD, bukanlah proses yang berdiri sendiri, namun merupakan suatu satu kesatuan tahapan pelayanan pasien di IGD termasuk aspek pre-hospital. Tingginya angka kematian di IGD ini disebabkan oleh beberapa hal yaitu berkaitan dengan budaya masyarakat, sarana prasarana pengiriman pasien, kesiapan fasilitas kesehatan yang merujuk, penanda yang kurang, tim merujuk pasien yang belum tersedia, kompetensi sumber daya manusia IGD yang kurang, SPO belum dilaksanakan dengan baik, dan komite mutu yang belum berfungsi dengan baik. Pengembangan sistem penanganan kegawatan berbasis wilayah yang terintegrasi dan komprehensif perlu dikembangkan mengingat pentingnya kecepatan dan ketepatan pelayanan dalam fase yang pendek sebagai faktor utama yang mempengaruhi mortalitas pada kegawatan.

The Bulletin of the World Health Organization. 2006; 84(4): 314-319.

4. Hayden C, Burlingame P, Thompson $\mathrm{H}$, and Sabol VK. Improving Patient Flow in the Emergency Department by Placing a Family Nurse Practitioner in Triage: $A$ Quality-Improvement Project. Journal of Emergency Nursing. 2014; 40(4): 346-351.

5. Richardson DB. Increase in Patient Mortality at 10 Days Associated with Emergency Department Overcrowding. Medical Journal of Australia. 2006; 184(5): 213-216.

6. Velianoff GD. Overcrowding and Diversion in the 
Emergency Department: The Health Care Safety Net Unravels. Nursing Clinics of North America. 2002; 37(1): 59-66.

7. Derlet RW and Richards JR. Overcrowding in the Nation's Emergency Departments: Complex Causes and Disturbing Effects. Annals of Emergency Medicine. 2000; 35(1): 63-68.

8. Kurnia E dan Yusanto D. Perbandingan Tingkat Kepuasan Keluarga Pasien Gawat Darurat dan Gawat Non Darurat terhadap Mutu Pelayanan Kesehatan di UGD RS. Baptis Batu. Jurnal Penelitian STIKES RS Baptis Kediri. 2012; 3(2): 78-84.

9. Lu TC, Tsai CL, Lee CC, et al. Preventable Deaths in Patients Admitted from Emergency Department. Emergency Medicine Journal. 2006; 23(6): 452-455.

10. World Health Organization. World Health Statistic 2010. France: WHO; 2010.

11. Djasri H dan Errisa B. Hospital Mortality Reduction Program. (O n I i n e 2013 . http://mutupelayanankesehatan.net/index.php/beri ta/34-hospital-mortality-reduction-program.

12. Hayward RA and Hofer TP. Estimating Hospital Deaths Due to Medical Errors: Preventability is in the Eye of the Reviewer. Journal of the American Medical Association. 2001; 286(4): 415-420.

13. Behal R and Finn J. Understanding and Improving Inpatient Mortality in Academic Medical Centers. Academic Medicine: Journal of the Association of American Medical Colleges. 2009; 84(12): 1657-1662.

14. Menteri Kesehatan Republik Indonesia. Keputusan Menteri Kesehatan Republik Indonesia tentang Standar Instalasi Gawat Darurat (IGD) Rumah Sakit Nomor: 856/Menkes/SK/IX/2009. Jakarta: Menteri Kesehatan RI; 2009.

15. Menteri Kesehatan Republik Indonesia. Keputusan Menteri Kesehatan Republik Indonesia tentang Standar Minimal Pelayanan Rumah Sakit Nomor: 129/Menkes/SK/II/2008. Jakarta: Menteri Kesehatan $\mathrm{Rl} ; 2008$.

16. Horton LA. Calculating and Reporting Healthcare Statistics. 3rd edition. Chicago: American Health Information Management Association Press; 2007.

17. Rahmawati AF dan Supriyanto S. Health Service Quality Based On Dabholkar Dimension At Ward Room Of Internal Disease. Journal Administrasi Kesehatan Indonesia. 2013; 1(2).

18. Hanafiah MJ dan Amir A. Etika Kedokteran dan Hukum Kesehatan. Edisi 4. Jakarta: Penerbit Buku kedokteran EGC; 1999.
19. Susilawati D. Hubungan Waktu Prehospital dan Nilai Tekanan Darah dengan Survival dalam $6 \mathrm{Jam}$ Pertama pada Pasien Cedera Kepala Berat di IGD RSUP. Dr. M. Djamil Padang Tahun 2010. [Repository]. Universitas Andalas, Padang. 2010.

20. Sitorus RJ. Faktor-faktor Risiko yang Mempengaruhi Kejadian Stroke pada Usia Muda Kurang dari 40 Tahun (Studi Kasus di Rumah Sakit di Kota Semarang). Jurnal Epidemiologi. Unpublish. 2008.

21. Kazmierski R. Predictors of Early Mortality in Patients with Ischemic Stroke. Expert Review of Neurotherapeutics. 2006; 6(9): 1349-1362.

22. $\mathrm{Wu} \mathrm{X}$, Zhu B, Fu L, et al. Prevalence, Incidence, and Mortality of Stroke in the Chinese Island Populations: A Systematic Review. PLoS One. 2013; 8(11).

23. Hankey GJ. Secondary Stroke Prevention. The Lancet Neurology. 2014; 13(2): 178-194.

24. Ryan D and Harbison J. Stroke as a Medical Emergency in Older People. Reviews in Clinical Gerontology. 2011; 21(1): 45-54.

25. Liu M, Wu B, Wang W-Z, Lee L-M, Zhang S-H, and Kong L-Z. Stroke in China: Epidemiology, Prevention, and Management Strategies. The Lancet Neurology. 2007; 6(5): 456-464.

26. Poungvarin N. Stroke in the Developing World. The Lancet. 1998; 352: SIII19-22.

27. Horner RD, Day GM, Lanier AP, Provost EM, Hamel RD, and Trimble BA. Stroke Mortality among Alaska Native People. American Journal of Public Health. 2009; 99(11): 1996-2000.

28. Soejoeti SZ. Konsep Sehat, Sakit dan Penyakit dalam Konteks Sosial Budaya. Majalah Cermin Dunia Kedokteran. 2005; 149.

29. Kementerian Kesehatan. Pedoman Teknis Bangunan Rumah Sakit Ruang Gawat Darurat. Jakarta: Kementerian Kesehatan; 2012.

30. Figgis K, Slevin O, Cunningham JB. Investigation of Paramedics' Compliance with Clinical Practice Guidelines for the Management of Chest Pain. Emergency Medicine Journal. 2010; 27(2): 151- 155.

31. Gonzalez Echeverri G. A Model for Improving Emergency Services of Hospital Universitario San Vicente de Paul, Medellin-Colombia. [Theses]. McGill University, Quebec. 2000.

32. Clark M, Spry E, Daoh K, Baion D, and Skordis-Worrall J. Reductions in Inpatient Mortality Following Interventions to Improve Emergency Hospital Care in Freetown, Sierra Leone. PLoS One. 2012; 7(9). 